\title{
A raridade das espécies arbóreas de Lauraceae no planalto do Estado de Santa Catarina, Brasil
}

\author{
Cláudia Fontana ${ }^{1,4}$, André Luís de Gasper ${ }^{2}$ e Lúcia Sevegnani ${ }^{3}$
}

Recebido: 16.12.2015; aceito: 10.06.2016

\begin{abstract}
The rarity of tree species of Lauraceae on the plateau of Santa Catarina State, Brazil). The rare species are particularly important from the point of view of conservation ecology and evolutionary biology, and often become the focus for policy decisions. The objective was to evaluate the Lauraceae rarity sampled by the Floristic Forest Inventory of Santa Catarina in Deciduous Forest (DF) and Araucaria Forest (AF). Data were collected in 234 sampling units of 0.40 ha each, recording trees with diameter at breast height $\geq 10 \mathrm{~cm}$. We used Rabinowitz's methodology to segregate rare and common species, considering three variables: geographic distribution, habitat specificity, and population size. Of the 37 species, $59.46 \%$ were rare and $40.54 \%$ were common. $56.76 \%$ of the species were eurytopic and $59.46 \%$ euryecious. $2.70 \%$ of the species were exclusive of DF, $67.57 \%$ exclusive of AF, and $29.73 \%$ occurred in both. This analysis contributed to the understanding of the rarity of the species in the studied region and it can also contribute to conservation actions for this family on Santa Catarina plateau, since most species are somewhat rare and intense forest fragmentation is the current scenario.
\end{abstract}

Keywords: analysis of rarity, Atlantic Forest, canelas

RESUMO - (A raridade das espécies arbóreas de Lauraceae no planalto do Estado de Santa Catarina, Brasil). As espécies raras são particularmente importantes do ponto de vista da conservação, ecologia e biologia evolutiva, além de ser frequentemente o foco para decisões políticas. O objetivo do trabalho foi avaliar a raridade de Lauraceae amostradas pelo Inventário Florístico Florestal de Santa Catarina na Floresta Estacional Decidual e na Floresta Ombrófila Mista. Coletaram-se dados em 234 unidades amostrais com 0,40 ha cada, registrando-se árvores com diâmetro na altura de $1,30 \mathrm{~m} \geq 10 \mathrm{~cm}$. Foi utilizada a metodologia Rabinowitz para segregar as espécies em raras ou comuns, considerando três variáveis: distribuição geográfica, especificidade por habitat e tamanho populacional. Das 37 espécies, 59,46\% apresentaram raridade e 40,54\% foram comuns. Classificou-se $56,76 \%$ das espécies como euritópica e 59,46\% eurioica. Das espécies, 2,70\% foram exclusivas da Floresta Estacional Decidual, 67,57\% exclusivas da Floresta Ombrófila Mista e 29,73\% ocorreram em ambas. Esta análise colaborou para a compreensão da raridade das espécies da região estudada e pode contribuir para ações de conservação dessa família no planalto catarinense, uma vez que a maior parte das espécies é de alguma forma rara e o cenário atual é de intenso processo de fragmentação florestal. Palavras-chave: análise de raridade, Floresta Atlântica, canelas

\section{Introdução}

As espécies raras são particularmente importantes do ponto de vista da conservação, ecologia e biologia evolutiva, além de ser frequentemente o foco para decisões políticas (Lim et al. 2012). Embora a raridade ainda não seja compreendida da mesma forma entre os pesquisadores, no contexto de biologia de populações e comunidades ela é habitualmente empregada no sentido de restrito (Rabinowitz et al. 1986, Gaston 1994, Caiafa \& Martins, 2010, Lim et al. 2012), sendo caracterizadas como raras as espécies endêmicas e com pequeno tamanho populacional (Gaston 1994) ou aquelas representadas por apenas um indivíduo, denominadas espécies singleton (Gaston 1994, Lim et al. 2012). No entanto, aliar a prática à teoria tem sido um desafio para os pesquisadores e tem instigado os ecologistas a tentarem compreender o fenômeno

1. Universidade do Vale do Rio dos Sinos, Programa de Pós-graduação em Conservação e Manejo da vida silvestre, Avenida Unisinos, 950, Cristo Rei, 93022-000 São Leopoldo, RS, Brasil

2. Universidade Regional de Blumenau, Departamento de Ciências Naturais, Herbário Dr. Roberto Miguel Klein, Rua Antônio da Veiga, 140, Victor Konder, 89012-900 Blumenau, SC, Brasil

3. Universidade Regional de Blumenal, Departamento de Ciências Naturais, Rua Antônio da Veiga, 140, Victor Konder, 89012-900 Blumenau, SC, Brasil. In memorian

4. Autor para correspondência: claudiafontanabio@gmail.com 
da raridade em amostras de biodiversidade (Lim et al. 2012). Rabinowitz et al. (1986) consideram que na ecologia a raridade não é um conceito exatamente fechado, mas sim pode apresentar gradientes, variando entre casos extremos e mais brandos de raridade (Rabinowitz et al. 1986). Dessa forma, aqueles autores apresentam uma alternativa frente ao conceito de raridade baseado em espécies singleton, propondo segregar a raridade em formas de raridade e espécies ditas comuns, tomando por base três variáveis compartilhadas entre as espécies: distribuição geográfica, especificidade por habitat e tamanho populacional. Essa metodologia para análise de raridade tem sido utilizada mundialmente por vários pesquisadores (Pitman et al. 1999, Broennimann et al. 2005, Drever et al. 2010, Caiafa \& Martins, 2010, Fontana \& Sevegnani 2012, Fontana et al. 2014) e pode retornar informações relevantes quanto à flora regional. O conhecimento dos gradientes de raridade é importante, pois possibilita distinguir onde devem ocorrer ações prioritárias de conservação (Drever et al. 2010).

Dentre as espécies que comumente constam em listas de ameaçadas, ou seja, aquelas cujas populações estão decrescendo a ponto de colocá-las em alto risco de desaparecimento na natureza em futuro próximo, incluem-se as Lauraceae, comumente conhecidas como canelas (Ministério do Meio Ambiente 2008), tornando pertinente a análise de raridade para esta família. Lauraceae é predominantemente pantropical, composta por cerca de 2.750 espécies, distribuídas em 50 gêneros (Rohwer 1993, Judd et al. 2009). No Brasil ocorrem 24 gêneros, sendo três endêmicos, e 441 espécies (Quinet et al. 2016) distribuídas em sua maior parte nas Florestas Pluviais e também nas Restingas e Cerrados (Barroso et al. 2002). Muitas das espécies são endêmicas, inclusive algumas endêmicas da Mata Atlântica (Lista de Espécies da Flora do Brasil 2016). Esta família tem relevante importância econômica, comportando muitas espécies madeiráveis, bem como produtoras de especiarias, substâncias e óleos essenciais (Reitz et al. 1978, Judd et al. 2009). Suas espécies são também ecologicamente importantes funcional e estruturalmente (Moraes 2005). As espécies de Lauraceae ocorrem em diferentes associações com outras espécies, em especial na Floresta Ombrófila Mista (Klein 1978). Apesar de sua reconhecida importância econômica e na estrutura das florestas (Reitz et al. 1978), as espécies são de difícil delimitação e poucos são os trabalhos envolvendo especificamente a família e suas condicionantes ecológicas requeridas. Estudos ecológicos abordando especificamente Lauraceae para o sul do Brasil ainda são escassos, principalmente para Santa Catarina, onde as principais publicações compreendem o Projeto Madeira de Santa Catarina (Reitz et al. 1978) e os fascículos da Flora Ilustrada Catarinense (FIC) (Vattimo-Gil 1979, Pedralli 1987). Os fascículos da FIC abordam os gêneros Aiouea, Aniba, Cryptocarya, Endlicheria, Licaria e Nectandra (Vattimo-Gil 1979, Pedralli 1987), entre outros gêneros, sendo que Ocotea, muito expressivo no planalto catarinense, não foi contemplado na FIC. Reitz et al. (1978) citam a ocorrência de 24 espécies de lauráceas para o planalto catarinense, entre elas oito de Ocotea. Esse panorama gera preocupação quanto à conservação atual das lauráceas em geral, uma vez que o planalto de Santa Catarina está sobre grande pressão de uso (Klein 1978, Vibrans et al. 2008, Vibrans et al. 2013a, 2013b).

Para avaliar se as espécies de Lauraceae presentes no planalto catarinense são predominantemente raras, foi utilizada a base de dados compilada pelo Inventário Florístico Florestal de Santa Catarina (IFFSC) (Vibrans et al. 2008, Vibrans et al. 2013a, 2013b), cujo trabalho tem se destacado como modelo para outros estados no escopo da execução de inventários florestais.

Espera-se que os resultados possam subsidiar ações de conservação e/ou manejo sustentável das espécies de Lauraceae presentes no planalto catarinense, bem como dos ecossistemas que as contém, e servir de modelo para outros estados avaliarem sua flora.

\section{Material e métodos}

Área de estudo - A área de estudo abrange a extensão das fitofisionomias da Floresta Ombrófila Mista (M) e Floresta Estacional Decidual (C) no Estado de Santa Catarina (SC), que compreende a região do planalto catarinense $\left(26^{\circ} 42^{\prime} 48,75^{\prime \prime} \mathrm{S}\right.$ e $53^{\circ} 42^{\prime} 28,27^{\prime \prime} \mathrm{W}$ a $27^{\circ} 46^{\prime} 34,59^{\prime \prime} \mathrm{S}$ e $\left.49^{\circ} 21^{\prime} 59,00^{\prime \prime} \mathrm{W}\right)$.

De acordo com a classificação de Köppen (1948) o clima predominante na Floresta Ombrófila Mista é "mesotérmico úmido com verão fresco" $(\mathrm{Cfb})$ e na Floresta Estacional Decidual "mesotérmico úmido com verão quente" (Cfa). As temperaturas médias estão entre $17^{\circ} \mathrm{C}$ e $19^{\circ} \mathrm{C}$ e há ocorrência de geadas de 5 a 20 dias por ano (Nimer, 1971). As chuvas são bem distribuídas (Leite \& Klein 1990), com precipitação média entre $1.500 \mathrm{~mm}$ a $2.250 \mathrm{~mm}$ (Nimer 1971). 
No Sul do Brasil, diferentemente de outras regiões do país, o caráter estacional da vegetação da Floresta Estacional Decidual, que provoca a queda das folhas, é dado em função das baixas temperaturas no inverno e não em razão de períodos de estiagem (Oliveira-Filho et al. 2006, Schumacker et al. 2011).

Os exemplares férteis coletados estão depositados no Herbário Dr. Roberto Miguel Klein (FURB), em Blumenau, SC. Apenas quatros espécies foram identificadas com base em material vegetativo e não foram incorporadas, constatando como observada em campo.

Compilação de dados - A base de dados utilizada para este trabalho é proveniente do Inventário Florístico Florestal de Santa Catarina (IFFSC, Vibrans et al. 2013a), o qual inventariou 234 unidades amostrais (UAs), em área de Florestas Ombrófilas Mistas e Estacionais Deciduais, sendo que em 216 ocorreu pelo menos uma espécie de Lauraceae (figura 1). A alocação das UAs foi através de uma amostragem sistemática, distribuída em grade de $5 \times 5 \mathrm{~km}$, compreendendo 78 UAs para o subgrupo de formação da Floresta Estacional Decidual, e grade de $10 \times 10 \mathrm{~km}$, compreendendo 156 Uas, para a Floresta Ombrófila Mista (figura 1). Cada UA foi composta por um conglomerado básico com área total de $4.000 \mathrm{~m}^{2}$, totalizando 93,6 hectares, onde foram amostrados todos os indivíduos com diâmetro a altura do peito (DAP a 1,30m) $\geq 10 \mathrm{~cm}$ (Vibrans et al. 2013a).

Análise de dados - Para segregar as formas de raridade das espécies foi utilizada a grade de parâmetros proposta por Rabinowitz et al. (1986), gerando uma matriz com oito categorias, uma contendo espécies comuns e as outras sete abrigando as formas de raridade (tabela 1). Esse sistema de classificação partiu de três variáveis comuns entre as espécies: distribuição geográfica, especificidade por habitat e tamanho populacional. O gradiente crescente de raridade vai de 1 a 7 , sendo que a forma 7 é considerada pelos autores do método a mais severa ou ameaçada (Rabinowitz et al. 1986).

Para a variável distribuição geográfica, utilizou-se o gradiente longitudinal em toda a extensão de ocorrência da Floresta Ombrófila Mista e Floresta Estacional Decidual que compreende o planalto no Estado (figura 1). A longitude foi analisada a cada 30 ' ou meio grau, equivalendo a $55 \mathrm{~km}$. Dessa forma, as UAs do IFFSC (2010) perfazem onze faixas longitudinais possíveis nesses subgrupos de formação. A classificação em "ampla distribuição geográfica" foi aplicada à espécie ocorrente em três ou mais faixas longitudinais, refletindo uma extensão de distribuição superior a $111 \mathrm{~km}$. Para a classificação como "restrita distribuição geográfica" foi considerada a ocorrência da espécie em duas ou apenas uma faixa longitudinal, ou seja, presente em uma extensão máxima de $110 \mathrm{~km}$.

Para a variável especificidade por habitat considerou-se o sistema hierárquico de classificação da vegetação proposto pelo Instituto Brasileiro de Geografia e Estatística (IBGE 2012) no que se refere às faixas altitudinais. No nível de "subgrupo de formação" foram consideradas a Floresta Ombrófila Mista (M) e a Floresta Estacional Decidual (C) e no nível de "formação propriamente dita" as três faixas de altitude entre as latitudes $24^{\circ} \mathrm{S}$ a $32^{\circ} \mathrm{S}$ onde ocorrem estas duas fitofisionomias, a saber: Submontana (30 a $400 \mathrm{~m}$ - siglas Ms e Cs), Montana (entre $400 \mathrm{~m}$ a $1.000 \mathrm{~m}$ - siglas $\mathrm{Mm}$ e Cm) e Alto-montana (acima de $1.000 \mathrm{~m}$ de altitude - siglas $\mathrm{Ml} \mathrm{e} \mathrm{Cl)}$. Foi considerada como tendo habitat único aquela espécie que se apresentou em apenas uma faixa altitudinal dentre as três possíveis (Submontana, Montana e Alto-montana) e com habitat variado a espécie que ocorreu em duas ou mais faixas altitudinais.

Para a variável tamanho populacional considerou-se o número de indivíduos amostrados em cada UA. Dessa forma, a espécie que apresentou apenas um indivíduo na UA em que ocorreu, foi considerada escassa. Considerou-se abundante a espécie que esteve presente, em pelo menos uma das UAs, com dois ou mais indivíduos. Portanto, com a aplicação destes critérios foi possível segregar as espécies desta família em sete formas de raridade, além das consideradas comuns (tabela 1).

Para melhor compreender a classificação obtida, avaliou-se também a situação de endemismos das espécies conforme a Lista das Espécies da Flora do Brasil (Quinet et al. 2014) e suas distribuições entre os subgrupos de formação.

\section{Resultados}

Foram amostradas 37 espécies arbóreas de Lauraceae, distribuídas em seis gêneros (tabela 2). O gênero com maior riqueza foi Ocotea com 20 espécies, seguido de Nectandra (sete), Persea (quatro), Cinnamomum (três), Cryptocarya (duas) e Endlicheria (uma espécie) (tabela 2).

Do total das espécies uma (2,70\%), Ocotea laxa, foi exclusiva da Floresta Estacional Decidual, 25 $(67,57 \%)$ foram exclusivas da Floresta Ombrófila 
Mista e $11(29,73 \%)$ estiveram presentes nos dois subgrupos de formação analisados (tabela 2).

Seis formas de raridade foram encontradas, sendo que apenas a forma 3 não está presente na região avaliada (tabela 2). Um elevado grau de raridade foi constatado entre as espécies, sendo observado em $59,46 \%$ das espécies (22 spp.). Constatou-se 40,54\% como espécies comuns no planalto catarinense, cuja distribuição é ampla e também abundante (15 espécies).

Apesar da maior parte das espécies ter apresentado alguma forma de raridade, a característica predominante da família Lauraceae do planalto é o euritopismo, com $56,76 \%$ das espécies amplamente distribuídas no planalto (formas 1,2 e comuns) (tabela $3)$. Espécies com características estenotópicas, com restrita distribuição, perfizeram $43,24 \%$ da amostra (formas 4, 5, 6 e 7) (tabela 3).

Quanto à especificidade por habitat, 59,46\% das espécies são eurioicas, não apresentando preferência quanto ao habitat (formas 1, 4, 5 e comuns) e 40,54\% das espécies são estenoicas, com restrição quanto ao habitat em que vivem (formas 2, 6 e 7), ou seja, ocorrem em apenas um subgrupo de formação (tabela 3).

Outra característica desta família no planalto catarinense é que a maior parte das espécies está presente com grandes populações. Mesmo aquelas que

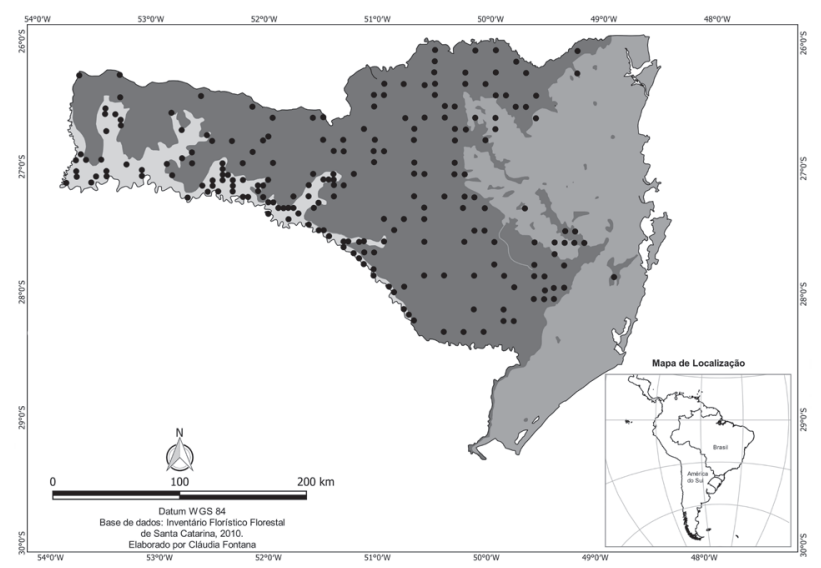

Figura 1. Distribuição das unidades amostrais onde a família Lauraceae foi amostrada no planalto catarinense e núcleos de Floresta Ombrófila Mista inseridos na Vertente Atlântica. Floresta Estacional Decidual, — Floresta Ombrófila Densa, - Floresta Ombrófila Mista.

Figure 1. Distribution of the sampling units of Lauraceae on the plateau of Santa Catarina and areas of Araucaria Forest on the Atlantic coast. Deciduous Forest, Atlantic Forest, — Floresta Araucaria Forest. foram categorizadas com alguma forma de raridade, estão em sua grande maioria nas formas que abrigam abundantes populações (formas 2, 4 e 6), consideradas pelos autores do método como de raridade mais branda (tabela 3). Isso quer dizer que a raridade das espécies que foram classificadas nestas formas está relacionada às características de especificidade por habitat e/ou amplitude de distribuição, uma vez que onde ocorrem são abundantes.

Dentre as espécies que apresentaram alguma raridade, a forma 6 é a mais frequente no planalto, com $24,32 \%$ das espécies assim distribuídas. Essa forma compreende espécies que ocorrem em pequena amplitude geográfica, têm restrições quanto ao habitat, porém onde ocorrem, ocorrem com muitos indivíduos. Entre as espécies categorizadas com a forma 6 destaca-se Ocotea floribunda. A forma 5 apresentou apenas uma espécie $(2,70 \%)$, Ocotea glaziovii (tabelas 2 e 3). As formas 1, 2, 4 e 7 estiveram presentes com três espécies cada $(8,11 \%$ cada) (tabelas 2 e 3). A forma considerada a mais severa pelo método Rabinowitz et al. (1986) é a forma 7, onde foram classificadas três espécies, sendo Ocotea nutans, Ocotea villosa e Persea venosa.

\section{Discussão}

Das espécies classificadas com alguma forma de raridade $63,64 \%$ (14) são endêmicas e 36,36\% (8 espécies) não são endêmicas do Brasil (Quinet et al. 2015). Das espécies classificadas como comuns $60 \%$ (9) não são endêmicas e 40\% (6 espécies) são endêmicas (Quinet et al. 2015). Esse resultado evidencia uma relação entre a raridade, pelo viés do método aplicado, e o endemismo atribuído às espécies analisadas. Dessa forma os resultados encontrados para as espécies raras e comuns estão em congruência com os dados apresentados pela Lista de Espécies da Flora do Brasil (Quinet et al. 2015), estando o percentual das espécies endêmicas de acordo com as classificadas raras, e as comuns de acordo com aquelas não endêmicas da mesma lista (tabela 2).

Embora as espécies comuns representem a menor parte de Lauraceae no planalto de SC, é necessário atenção para com elas, pois, segundo Broennimann et al. (2005), espécies não endêmicas são susceptíveis de receber alta prioridade de conservação somente quando se tornarem altamente ameaçadas em escala global. Conforme o mesmo autor, o problema de não se dar atenção a essas espécies é que podem se tornar raras em escala nacional, justamente devido aos 
Tabela 1. Grade de parâmetros utilizada para classificar as formas de raridades das espécies baseada em Rabinowitz et al. (1986).

Table 1. Grade of parameters used to classify forms of species rarity according to Rabinowitz et al. (1986).

\begin{tabular}{|c|c|c|c|c|c|}
\hline \multirow{3}{*}{\multicolumn{2}{|c|}{$\begin{array}{l}\text { Distribuição geográfica } \\
\\
\text { Especificidade de habitat } \\
\text { (Submontana, Montana, Alto-montana) }\end{array}$}} & \multicolumn{2}{|c|}{ Ampla (acima de $111 \mathrm{~km}$ ) } & \multicolumn{2}{|c|}{ Restrita (até $110 \mathrm{~km}$ ) } \\
\hline & & Variado & Único & Variado & Único \\
\hline & & ( $\geq 2$ habitats) & (1 habitat) & ( $\geq 2$ habitats) & (1 habitat) \\
\hline \multirow{2}{*}{$\mathrm{N}^{\mathrm{o}}$ de indivíduos } & $\begin{array}{l}\text { Abundantes } \\
\geq 2 \text { ind. } \mathrm{UA}^{-1}\end{array}$ & Espécies Comuns & Forma 2 & Forma 4 & Forma 6 \\
\hline & $\begin{array}{c}\text { Escassos } \\
1 \text { ind.UA } \text { UA }^{1}\end{array}$ & Forma 1 & Forma 3 & Forma 5 & Forma 7 \\
\hline
\end{tabular}

Fonte: Adaptado de Rabinowitz et al. (1986).

Tabela 2. Lista das espécies arbóreas da família Lauraceae com suas formas de raridade, quantidade de unidades amostrais (UAs) em que ocorreram, número de indivíduos ( $\mathrm{N}^{\circ}$ Indiv.), subgrupos de formação onde ocorrem e as endêmicas e não endêmicas do Brasil conforme Lista das Espécies da Flora do Brasil. Siglas das fitofisionomias conforme IBGE (2012): M: Floresta Ombrófila Mista, C: Floresta Estacional Decidual. O voucher representa o barcode do exemplar registrado no Herbário FURB.

Table 2. List of trees of the family Lauraceae with their forms of rarity, number of sampling units (UAs) in which they occurred, number of individuals (No Indiv.), subgroups where they occur, and endemic and non-endemic species of Brazil according to List of Species of Flora of Brazil. M: Araucaria Forest, C: Deciduous Forest. Voucher number is the accession barcode in FURB herbarium.

\begin{tabular}{|c|c|c|c|c|c|c|}
\hline Espécie & Forma & UAs & $\mathrm{N}^{\mathrm{o}}$ Indiv. & Ocorre em & Endêmica & Voucher \\
\hline Cinnamomum amoenum (Nees) Kosterm. & Comum & 64 & 294 & Ambas & Não & FURB26887 \\
\hline Cinnamomum glaziovii (Mez) sterm. & Comum & 16 & 40 & M & Sim & FURB02000 \\
\hline $\begin{array}{l}\text { Cinnamomum sellowianum (Nees \& Mart.) } \\
\text { osterm. }\end{array}$ & Comum & 12 & 32 & M & Sim & FURB26912 \\
\hline Cryptocarya aschersoniana $\mathrm{Mez}$ & Comum & 46 & 214 & Ambas & Não & FURB26940 \\
\hline Cryptocarya mandioccana Meisn. & F6 & 3 & 20 & M & Sim & FURB02008 \\
\hline Endlicheria paniculata (Spreng.) J.F. Macbr. & F4 & 4 & 8 & Ambas & Não & FURB26976 \\
\hline Nectandra angustifolia (Schrad.) Nees & F6 & 1 & 13 & M & Não & Observada em campo \\
\hline Nectandra grandiflora Nees \& Mart. ex Nees & Comum & 17 & 112 & Ambas & Sim & FURB27060 \\
\hline Nectandra lanceolata Nees & Comum & 105 & 792 & Ambas & Sim & FURB27069 \\
\hline Nectandra megapotamica (Spreng.) Mez & Comum & 133 & 1.424 & Ambas & Não & FURB27114 \\
\hline Nectandra membranacea (Sw.) Griseb. & F2 & 4 & 8 & Ambas & Não & FURB27161 \\
\hline Nectandra oppositifolia Nees & Comum & 5 & 15 & M & Não & FURB27398 \\
\hline Nectandra puberula (Schott) Nees & F6 & 2 & 13 & M & Sim & FURB27197 \\
\hline Ocotea bicolor Vattimo-Gil & $\mathrm{F} 2$ & 6 & 70 & M & Não & FURB27222 \\
\hline Ocotea catharinensis $\mathrm{Mez}$ & $\mathrm{F} 1$ & 4 & 4 & M & Não & FURB27249 \\
\hline Ocotea corymbosa (Meisn.) Mez & Comum & 10 & 33 & M & Não & FURB04249 \\
\hline Ocotea daphnifolia (Meisn.) Mez & F6 & 3 & 5 & M & Sim & FURB02024 \\
\hline Ocotea diospyrifolia (Meisn.) Mez & Comum & 42 & 126 & Ambas & Não & FURB02025 \\
\hline Ocotea elegans $\mathrm{Mez}$ & F2 & 3 & 11 & M & Sim & FURB27308 \\
\hline Ocotea floribunda (Sw.) Mez & F6 & 3 & 6 & M & Não & Observada em campo \\
\hline
\end{tabular}


Tabela 2 (continuação)

\begin{tabular}{lcccccc}
\hline Espécie & Forma & UAs & N $^{\circ}$ Indiv. & Ocorre em & Endêmica & Voucher \\
\hline Ocotea glaziovii Mez & F5 & 2 & 2 & M & Sim & FURB27313 \\
Ocotea indecora (Schott) Mez & F4 & 7 & 19 & M & Não & FURB27430 \\
Ocotea lancifolia (Schott) Mez & F1 & 5 & 5 & M & Não & FURB27444 \\
Ocotea laxa (Nees) Mez & F6 & 1 & 4 & C & Sim & FURB27446 \\
Ocotea nectandrifolia Mez & F6 & 1 & 3 & M & Sim & FURB27470 \\
Ocotea nutans (Nees) Mez & F7 & 1 & 1 & M & Sim & FURB27493 \\
Ocotea odorifera (Vell.) Rohwer & Comum & 20 & 76 & Ambas & Sim & FURB02037 \\
Ocotea porosa (Nees \& Mart.) Barroso & Comum & 47 & 490 & M & Não & FURB27563 \\
Ocotea puberula (Rich.) Nees & Comum & 154 & 1.564 & Ambas & Não & FURB27585 \\
Ocotea pulchella (Nees) Mez & Comum & 93 & 551 & Ambas & Não & FURB27658 \\
Ocotea silvestris Vattimo-Gil & F6 & 3 & 4 & M & Sim & FURB27742 \\
Ocotea vaccinioides (Meisn.) Mez & F4 & 3 & 7 & M & Sim & FURB27832 \\
Ocotea villosa Kosterm. & F7 & 1 & 1 & M & Sim & FURB02048 \\
Persea alba Nees \& Mart. & F6 & 2 & 8 & M & Sim & FURB02049 \\
Persea major (Meisn.) L.E.Kopp & F1 & 4 & 4 & M & Sim & Observada em campo \\
Persea venosa Nees \& Mart. & F7 & 1 & 1 & M & Sim & Observada em campo \\
Persea willdenovii Kosterm. & Comum & 10 & 28 & M & Sim & FURB27827 \\
\hline
\end{tabular}

fatores de degradação e fragmentação diversificados que, por consequência, podem levar a extinções simultâneas em diversos países.

A constatação de que a maior parte das espécies de lauráceas está presente no planalto com grandes populações, sendo assim consideradas de raridade mais branda, pode ser utilizado por gestores ambientais quando houver escassez de recursos para proteção ou conservação, por exemplo. Neste contexto, o foco inicial podem ser as espécies cuja raridade se apresentou mais severa (formas 1, 5 e 7), em detrimento das raridades mais brandas (formas 2, 4, 6 e comuns), embora se saiba que o ideal é dar atenção a todas as formas, inclusive as comuns. Cabe ressaltar que a abundância aqui descrita está relacionada aos critérios estabelecidos no delineamento amostral, no qual uma espécie é considerada abundante quando ocorre com mais de um indivíduo em pelo menos uma UA. Ainda assim, essa elucidação do gradiente de raridade se apresenta como uma interessante vantagem do método proposto por Rabinowitz et al. (1986). Drever et al. (2010) concluíram que o conceito abordado por Rabinowitz et al. (1986), sobre vários tipos de raridade, implica em formas de gestão diferenciadas entre as formas de raridade e pode fornecer orientações úteis para a conservação da biodiversidade.

Sobre as espécies destacadas como mais ameaçadas (forma 7), sendo elas Ocotea nutans,
Ocotea villosa e Persea venosa, Caiafa \& Martins (2010) classificaram Persea venosa como comum, Ocotea nutans com a forma 4 de raridade e não encontraram Ocotea villosa em suas amostras. Conforme a Lista de Espécies da Flora do Brasil (2016), Ocotea villosa é endêmica da Mata Atlântica, mas com citação apenas para o Sudeste, nos Estados de Rio de Janeiro e Minas Gerais. Conforme a mesma fonte Ocotea nutans é endêmica, ocorre desde o Nordeste até o Sul, porém, com limite austral até o Estado do Paraná, agora ampliado para Santa Catarina. Ocotea nutans e $O$. villosa também não constam na lista do Projeto Madeira de Santa Catarina (Reitz et al. 1978), inferindo-se que são de fato raras localmente ou, por outro lado, que possa haver uma deficiência de amostragem para essa espécie. No entanto, para esclarecer a presença destas espécies no planalto catarinense fazem-se necessários outros estudos.

Dentre as espécies comuns estão aquelas citadas por Klein (1978) e Reitz et al. (1978) como muito abundantes nesta região, como Nectandra lanceolata, Nectandra megapotamica e Ocotea puberula, sendo que as duas últimas ultrapassaram 1.400 indivíduos amostrados para cada uma (tabela 2). Essas espécies também foram classificadas como comuns na análise realizada por Caiafa \& Martins (2010) para a porção meridional da Floresta Atlântica (Floresta Ombrófila Densa), constatando-se que são de ampla distribuição, 
generalistas e abundantes em todo o Domínio da Floresta Atlântica. De fato, Pedralli (1987) descreve que as espécies de Nectandra são abundantes em quase todas as florestas catarinenses, e estão presentes em associações pioneiras, juntamente com Ocotea puberula, uma das espécies secundárias iniciais mais comuns do planalto sul-brasileiro (Carvalho 2003). Esse resultado demonstra que estas espécies possuem grande plasticidade e que, apesar da intensificação da degradação dos fragmentos florestais desde a década de 70, estas espécies ainda mantêm as grandes populações relatadas àquela época para o planalto (Klein 1978, Reitz et al. 1978). Por outro lado, é igualmente possível que estas espécies, em razão de seu caráter pioneiro e secundário inicial, estejam se beneficiando da degradação e fragmentação das florestas do planalto catarinense, e por isso apresentem abundantes populações.

Também foram segregadas como comuns as espécies Ocotea odorifera e Ocotea porosa, que constam na Lista Oficial das Espécies da Flora Brasileira Ameaçada de Extinção (Ministério do Meio Ambiente 2014), porém foram abundantes localmente. Estas espécies foram amostradas em várias UAs e com relevantes populações, especialmente Ocotea porosa (tabela 2). Caiafa e Martins (2010) encontraram Ocotea porosa com a forma 4 de raridade e Ocotea odorifera como comum na porção meridional da Floresta Ombrófila Densa. Carvalho (2003) corrobora esta condição descrevendo que Ocotea odorifera é principalmente de Floresta Ombrófila Densa e encontrada em menor número nas florestas estacionais.
Já Ocotea porosa é descrita como característica da Floresta Ombrófila Mista, onde, por vezes, forma densas populações chamadas imbuiais (Carvalho 2003). Porém, há que se considerar que estas espécies tem elevado valor de mercado e então passam a ser ameaçadas, podendo vir a se tornarem raras, não em razão de suas populações, mas por consequência da elevada exploração do seu produto madeireiro.

À luz do método aqui aplicado, a categorização das espécies comuns para a Floresta Estacional Decidual revela a subjetividade dos critérios empregados, como, por exemplo, Nectandra oppositifolia, amostrada com 15 indivíduos e em cinco UAs, e no outro extremo Ocotea puberula, com 1.564 indivíduos, em 154 UAs (tabela 2). O caráter negativo da subjetividade dos critérios de segregação foi também constatado por outros pesquisadores (Izco 1998, Broennimann et al. 2005, Caiafa \& Martins 2010). Ainda assim, para muitos pesquisadores, a metodologia é claramente uma melhoria em comparação ao conceito de raridade única e fornece uma avaliação preliminar útil da importância relativa de cada tipo de raridade (Izco 1998, Ricklefs 2000, Murray et al. 2002, Broennimann et al. 2005, Caiafa \& Martins 2010, Drever et al. 2010).

\section{Conclusão}

A presente análise de raridade, que permitiu combinar as variáveis distribuição geográfica, especificidade por habitat e número de indivíduos, auxilia na compreensão da raridade das espécies da região estudada e contribui com a gestão da

Tabela 3. Grade de parâmetros para classificação de formas de raridades e distribuição percentual das espécies de Lauraceae em cada forma.

Table 3. Grade of parameters for classifying forms of rarity and percentual distribution of species of Lauraceae in each form.

\begin{tabular}{|c|c|c|c|c|c|}
\hline \multicolumn{2}{|c|}{ Distribuição geográfica } & \multicolumn{2}{|c|}{$\begin{array}{l}\text { Ampla } \\
56,76 \%\end{array}$} & \multicolumn{2}{|c|}{$\begin{array}{l}\text { Restrita } \\
43,24 \%\end{array}$} \\
\hline $\begin{array}{l}\text { Especificidade de } \\
\mathrm{V}=59,46 \% ; \mathrm{U}=\end{array}$ & $\begin{array}{l}\text { bitat } \\
, 54 \%\end{array}$ & Variado $(\mathrm{V})$ & Único (U) & Variado & Único \\
\hline \multirow{4}{*}{$\mathrm{N}^{\mathrm{o}}$ de indivíduos } & \multirow{3}{*}{$\begin{array}{c}\text { Abundantes } \\
81,08 \%\end{array}$} & Espécies Comuns & Forma 2 & Forma 4 & Forma 6 \\
\hline & & $40,54 \%$ & $8,11 \%$ & $8,11 \%$ & $24,32 \%$ \\
\hline & & (15) & (3) & (3) & (9) \\
\hline & $\begin{array}{c}\text { Escassos } \\
18,92 \%\end{array}$ & $\begin{array}{c}\text { Forma } 1 \\
8,11 \% \\
(3)\end{array}$ & Forma 3 & $\begin{array}{c}\text { Forma } 5 \\
2,70 \% \\
(1) \\
\end{array}$ & $\begin{array}{c}\text { Forma } 7 \\
8,11 \% \\
(3) \\
\end{array}$ \\
\hline
\end{tabular}

Fonte: Adaptado de Rabinowitz et al. (1986). 
conservação das lauráceas do planalto catarinense, bem como pode ser utilizada como subsídio para elaboração de listas de espécies ameaçadas, uma vez que clarifica o grau de vulnerabilidade de cada espécie na região.

\section{Agradecimentos}

Os autores agradecem à CAPES pela concessão de bolsa de Mestrado em Engenharia Ambiental (FURB), ao Inventário Florístico Florestal de Santa Catarina (IFFSC) e FAPESC - Fundação de Amparo à Pesquisa e Inovação do Estado de Santa Catarina pela cessão dos dados, e à equipe que dele participou, bem como aos revisores anônimos e à editora, pelas valiosas contribuições. Os mesmos dedicam este trabalho à Lucia Sevegnani, que sempre lutou pela preservação das florestas catarinenses.

\section{Literatura citada}

Barroso, G.M., Guimarães, E.F., Ichaso, C.L.F., Costa, C.G. \& Peixoto, A.L. 2002. Sistemática de Angiospermas do Brasil. v. 1, 2 ed. Editora Universidade Federal de Viçosa, Viçosa.

Broennimann, O., Vittoz, P., Moser, D. \& Guisan, A. 2005. Rarity types among plant species with high conservation priority in Switzerland. Botânica Helvetica 2: $95-108$.

Caiafa, A.N. \& Martins F.R. 2010. Forms of rarity of tree species in the southern Brazilian Atlantic rainforest. Biodivers Conservation 19: 2597-2618.

Fontana, C., \& Sevegnani, L. 2012. Quais as espécies arbóreas comuns da Floresta Estacional Decidual de Santa Catarina? Revista de estudos ambientais 14: 74-88. Disponível em http://proxy.furb.br/ojs/index. $\mathrm{php} / \mathrm{rea} / \mathrm{article} / \mathrm{view} / 2454$ (acesso em 12-VII-2016).

Fontana, C., Gasper, A.L. \& Sevegnani, L. 2014. Espécies raras e comuns de Myrtaceae da Floresta Estacional Decidual de Santa Catarina, Brasil. Rodriguésia 3: 767-776.

Carvalho, P.E.R. 2003. Espécies arbóreas brasileiras. Embrapa Informação Tecnológica, Brasília.

Drever, C.R., Snider, J. \& Drever, M.C. 2010. Rare forest types in northeastern Ontario: a classification and analysis of representation in protected areas. Canadian Journal of Forest Research 40: 423-435.

Gaston J. 1994. Rarity. Chapman \& Hall, Londres.

Instituto Brasileiro de Geografia e Estatística - IBGE. 2012. Manual técnico da vegetação brasileira. 2 ed. Instituto Brasileiro de Pesquisas e Estatística, Rio de Janeiro.

Izco, J. 1998. Types of rarity of plant communities. Journal of Ecology Science 5: 641-646.

Judd, W.S., Campbell, C.S., Kellogg, E.A., Stevens, P.F. \& Donoghu, M.J. 2009. Sistemática Vegetal: um enfoque filogenético. 3 ed. Artmed, Porto Alegre.
Klein, R.M. 1978. Mapa fitogeográfico de Santa Catarina. Flora Ilustrada Catarinense, Itajaí.

Köppen, W. 1948. Climatologia: con un Estudio de los Climas de la Tierra. Fondo de Cultura Economica, México.

Leite, P. F. \& Klein, R.M. 1990. Vegetação. In: Instituto Brasileiro de Geografia e Estatística. Geografia do Brasil: região Sul. Fundação Instituto Brasileiro de Geografia e Estatística, Rio de Janeiro, pp. 113-150.

Lim, G.S., Balke, M. \& Meier, R. 2012. Determining species boundaries in a world full of rarity: singletons, species delimitation methods. Systematic Biology 1: $165-169$.

Lista de Espécies da Flora do Brasil. 2016. Projeto Reflora: flora do Brasil 2020. Disponível em http:// floradobrasil.jbrj.gov.br (acesso em 17-IV-2016).

Ministério do Meio Ambiente. 2014. Portaria n ${ }^{\circ} 443$, de 17 de dezembro de 2014. Espécies da Flora brasileira ameaçada de extinção. Ministério do Meio Ambiente, Brasília. Disponível em http://pesquisa.in.gov.br/ imprensa/jsp/visualiza/index.jsp?data $=18 / 12 / 2014 \&$ jornal $=1 \&$ pagina $=116 \&$ totalArquivos $=144($ acesso em 12-VII-2016).

Moraes, P.L.R. 2005. Sinopse das Lauráceas nos estados de Goiás e Tocantins, Brasil. Biotaneotropica, São Paulo 2: 2-17.

Murray, B.R., Thrall, P.H.A., Gill, M.M. \& Nicotra, A.B. 2002. How plant life-history and ecological traits relate to species rarity and commonness at varying spatial scales. Austral Ecology 27: 291-310.

Nimer, E. 1971. Climatologia da Região Sul do Brasil. Revista Brasileira de Geografia. 33: 3-65.

Oliveira-Filho, A.T., Jarenkow, J.A. \& Rodal, M.J.N. 2006. Floristic relationships of seasonally dry forests of eastern South America based on tree species distribution patterns. In: Pennington, R.T., Lewis, G.P. \& Ratter, J. A. (org.). Neotropical savannas and dry forests: plant diversity, biogeography and conservation. CRC Press, Boca Raton, pp. 151-184.

Pedralli, G. 1987. Lauráceas: Nectandra. In: R. Reitz. Flora Ilustrada Catarinense, Itajaí, pp. 55-93.

Pennington, R.T., Lavin, M. \& Oliveira Filho, A. 2009. Woody Plant Diversity, Evolution, and Ecology in the Tropics: perspectives from Seasonally Dry Tropical Forests. Evolution and Systematics 1:437-457.

Pitman N.C.A. Terborgh, J., Silman, M.R. \& Nuñez P.V. 1999. Tree species distributions in upper Amazonin forest. Ecology 8: 2651-2661.

Quinet, A., Baitello, J.B., Moraes, P.L.R., Assis, L. \& Alves, F.M. 2015. Lauraceae. In: R. Campostrini Forzza (org.). Lista de Espécies da Flora do Brasil. Jardim Botânico do Rio de Janeiro. Disponível em http:// floradobrasil.jbrj.gov.br/jabot/floradobrasil/FB143 (acesso em 09-V-2016). 
Rabinowitz, D., Cairns, S. \& Dillon, T. Seven forms of rarity and their frequency in the flora of the British Isles. 1986. In: Michael E. Soulé (ed). Conservation Biology: The Science of Scarcity and Diversity. Sinauer Associates, Michigan, pp. 182-204.

Reitz, R., Klein, R.M. \&, Reis, A. 1978. Projeto Madeira de Santa Catarina. Itajaí, Sellowia 28-30: 11-320.

Ricklefs, R.E. 2000. Rarity and diversity in Amazonian forest trees. Tree 3: 83-84.

Rohwer, J.G. 1993. Lauraceae. In: K. Kubitzki, J.G. Rohwer \& V. Bittrich (eds.). The families and general of vascular plants. v. 2. Springer-Verlag, Berlin.

Schumacker, M.V., Longhi, S.J.B., Brun, E.J. \& Kilka, R.V.A. 2011. Floresta Estacional Subtropical: caracterização e ecologia no rebordo do planalto meridional. Pallotti, Santa Maria.
Vattimo-Gil, I. 1979. Lauráceas: Cryptocarya, Endlicheria, Licaria, Aiouea, Aniba. In: R. Reitz. Flora Ilustrada Catarinense, Itajaí, pp. 3-50.

Vibrans, A.C., Uhlmann, A., Sevegnani, L., Marcolin, M., Nakajima, N., Grippa, C.R., Brogni, E. \& Godoy, M. B. 2008. Ordenação dos dados de estrutura da Floresta Ombrófila Mista partindo de informações do inventário florístico-florestal de Santa Catarina: resultados de estudo-piloto. Ciência Florestal 4: 511-523.

Vibrans, A.C., Sevegnani, L., Gasper, A.L. \& Lingner, D.V. 2013a. Inventário Florístico Florestal de Santa Catarina: Floresta Estacional Decidual. v. 2, Edifurb, Blumenau.

Vibrans, A.C., Sevegnani, L., Gasper, A.L. \& Lingner, D.V. 2013b. Inventário Florístico Florestal de Santa Catarina: Floresta Ombrófila Mista. v. 3, Edifurb, Blumenau. 